\title{
Research on the Spatio-temporal Database of the Sea Area Use based on Sea Lot Alternation
}

\author{
Baiqiong Liu, Min Xu, Qing Liu \\ School of Geographical Sciences, Nanjing Normal University, \\ Nanjing 210023, China
}

\begin{abstract}
The dynamic management of the sea area use spatiotemporal data is going to be highlighted. Through the analysis of the characteristics of the sea area use data, based on the research of TGIS and the advantages of existing spatio-temporal database model, this paper puts forward a design proposal of the sea area use spatio-temporal database .Focusing on the data organization and data storage management mechanism, the spatio-temporal database is divided into present database, historical database and alternative database. To fulfill the expression requirements for spatial, temporal, attribute information about sea area use data, the multi-table connected patterns is adapted to store the spatiotemporal data. The database also combined the sea lot connection index table to increase the query efficiency of sea area use spatiotemporal data. According to the design proposal of this paper, the storage space and redundancy has been reduced effectively in sea area use spatio-temporal database.
\end{abstract}

Keywords-TGIS; sea lot alternation;spatio-temporal database;

\section{INTRODUCTION}

Besides spatial characteristics and attribute characteristics, there are also distinctive temporal features in sea area use data. With the changes of the development of the sea use and the improvement of the utility level of the sea area, maritime right of use can be transferred or inherited according to law. When the deadline of sea use right is coming up, it can be terminated or renewal. The person who has the right to use sea area maybe change because of corporation merger, division or cooperation with others ${ }^{[1]}$. The dynamic management of sea area use spatiotemporal data includes many ways, such as the change of person who has the right to use sea area, the transformation of maritime space use type and region, which is an very important part in marine area management. Therefore, through the comprehensive consideration of space, time and attributes, so that spatial data and non-spatial data can reach the seamless integration. To meet the marine administrative department's needs, it's very important to achieve multi-tense and multispatial levels sea area use data management.

Temporal GIS has been widespread concerned as a new field of GIS research and application. Through spatio-temporal database to store and manage historical data, present data and future data effectively, it has a good application prospect in sea area use data's management ${ }^{[2]}$. Spatio-temporal database is the temporal GIS's key point, and it is very important to establish proper sea area use spatio-temporal database, which can provide perfect timing analysis function and effectively answer various problems connected with time. According to meet the marine administrative departments' needs of historical data query and retrospect, this paper analysis advantages of currently various spatio-temporal data models, take sea lot alternation as breakthrough point, put forwards an effective database organization methods in order to achieve the sea area use spatio-temporal data's analysis and management.

\section{THE CHARACTERISTICS OF SEA AREA USE DATA}

\section{A. Sea lot and Sea lot alternation}

The object of sea area use management is each of the sea use element, namely sea $\operatorname{lot}^{[1]}$. In the "Technical Specification of Sea Area Use Investigation", sea lot means a sea use unit which is closed by boundary lines. Sea lot is represented as a polygon with closed boundary in space. The inflection points of boundary line are the sea area use boundary points, and the connecting line between adjacent boundary points constitutes boundary line.

Many events can cause the ownership change of sea lot, such as sea area use allocation, marine use type change and ownership transfer, which constitutes sea lot alternation. When sea lot alternation happens, the related time, space and attribute characteristics changes accordingly. Among them, the time information includes the sea lot's creating time, dying time and alternation time; the space information includes sea lot's geographic location and shape, which is usually determined by boundary points coordinates; the attribute information includes sea area use ownership, the type and area of marine use, the price of sea area use and so on.

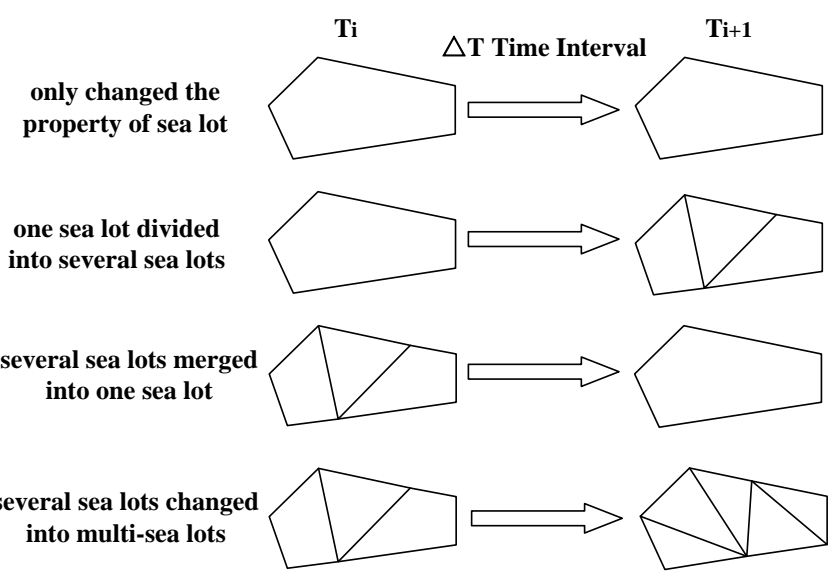

Fig.1 Basic types of sea lot alternations in time and space

Foundation :the Program of JiangSu Coastal Ocean Comprehensive Investigation and Evaluation under Contract No.JS-908-01-03 
In the change process of sea area use spatio-temporal data, there are four kinds of state changes, which includes only changed the property of sea lot, one sea lot divided into several sea lots, several sea lots merged into one sea lot, several sea lots changed into multi-sea lots and so on. No matter which kind of state change happens, it will cause the sea lot's temporal characteristics change. Figure 1 shows the basic types of sea lot alternations in time and space.

\section{B. Sea lot spatio-temporal data organization}

According to the analysis of types of sea lot alternations and processes, sea lot unit consists of spatial information, time information and attribute information. Three components can be described as:

$$
\mathrm{U}=\mathrm{F}(\mathrm{S}, \mathrm{T}, \mathrm{A})
$$

Among them, $\mathrm{S}$ is the spatial information, describing the shape of sea lot, the boundary line alignment, and the coordinates of inflection points, which is determined by a series of coordinates of sea lot's boundary points, expressed by $\mathrm{X}$ and $\mathrm{Y}$ coordinate. $\mathrm{T}$ is the time information, describing the sea lot's creating time, alternation time and dying time. $A$ is the attribute information, describing the indicators such as the sea lot ownership, the type of sea use, the corporate representative and so on. Indicators of those properties are not directly related to spatial characteristics of the sea lot.

Generally speaking, there are two ways to organize the spatio-temporal objects, which are multi-tables associated storage structure and single-sheet multi-fields storage structure. The method of single-sheet multi-fields structure stores the space, time and attribute information in a single data table, which may easily lead to data redundancy and not conducive to data query, analysis and updating operations. Therefore, this paper adopts the multi-tables associated storage structure to organize the sea lot data effectively. According to the characteristics of the sea use's frequent change, this mode can realize the expression of sea lot entity's geographic location, property characteristics and temporal features, which is easy to track the historical status and update changes of sea lot.

The space information is stored in the spatial characteristics table, time information is stored in the temporal characteristics table, and the property information is stored in the attribute characteristics table. Three table through the exclusive sea lot identification code to link and associate with each other, managing the sea area use spatio-temporal data dynamically (Figure 2).

\begin{tabular}{|c|c|c|}
\hline $\begin{array}{c}\text { Characteristics of } \\
\text { Space Table }\end{array}$ & $\begin{array}{c}\text { Characteristics of } \\
\text { Attribute Table }\end{array}$ & $\begin{array}{l}\text { Characteristics of } \\
\text { Temporal Table }\end{array}$ \\
\hline $\begin{array}{l}\text { Identification code } \\
\text { The shape of sea lot } \\
\text { The boundary line } \\
\text { The coordinates of } \\
\text { boundary points } \\
\text { The others...... }\end{array}$ & $\begin{array}{l}\text { Identification code } \\
\text { The type of sea use } \\
\text { Corporate representative } \\
\text { Ownership department } \\
\text { Certificate Number } \\
\text { The others...... }\end{array}$ & $\begin{array}{l}\text { Identification code } \\
\text { The generation time } \\
\text { The alternation time } \\
\text { The disappearance time } \\
\text { The others } \cdots \cdots .\end{array}$ \\
\hline
\end{tabular}

Fig.2 multi-tables associated of sea lot data

\section{The life cycle of sea lot}

According to the view of temporal GIS, each entity has its own process of emergency, development and disappearance.
The life cycle of sea lot means the effective time from generation to dying. In this sense, the sea lot's generation time, change time and disappearance time have special significance in the time information. In order to describe the life cycle of sea lot, it is indispensable to set three time fields which include creating time, alternative time and dying time.

When the sea lot changes, sometimes it's not simply disappeared, but participating in the new object generation. In the same way, when sea lot forms, sometimes it's not just appeared, but inherited from other sea lot. This inheritancerelationship between the sea lot's generation and alternation is called genetic relationship. The object before the sea lot alternation is called father-sea-lot, and the object after the sea lot alternation is called son-sea-lot. The change of father-sealot and the generation of son-sea-lot are triggered by the same event. In life cycle the sea lot has connections between father and son, so it's very important in sea lot's historical retrospect to record the genetic relationship of father and son in detail.

\section{THE DESIGN OF SPATIO-TEMPORAL DATABASE}

\section{A. Select the proper spatio-temporal data model}

At present, the main spatio-temporal data model includes spatio-temporal cube model, snapshots sequence model, base state with amendments, time-space composite model, object oriented spatio-temporal model, event-driven spatio-temporal model, three domain model and so on ${ }^{[3-9]}$.Among them, base state with amendments model is based on time and object oriented, which can well combined with object-oriented relational database. Adapting this model, the time table and object table are easily connected. For the element stored in the time table, it can be immediately checked out the ground-state variation meeting the query conditions.

Most of the changes about sea area use data occur only in the local one or a few adjacent sea lots. Because of its property of local discontinuity, and almost without regarding to topological relations, it is very appropriate to adapt the base state with amendments model to manage the sea area use spatio-temporal data, especially beneficial for the historical information query and recollection. Based on the above reason, this paper use the base state with amendments model to design the sea lot spatio-temporal database.

\section{B. Construct the sea area use spatio-temporal database}

As a result of added time dimension, the constant change of sea lot data lead to accumulated historical data. Those huge amounts of data caused bloated database, and in most cases, the operation of present data are more frequent, otherwise the historical data operation is relatively rare. To avoid the redundancy of data storage, and realize the query of sea area use status at a certain moment in history for a given area, the database is divided into present database, historical database and alternation database. The present data and historical data are stored separately in this paper. The present database store the current status of sea area use data, the historical database reflect the sea lot data's history, and the alternation database store the change information and genetic relationship of sea lot data, the concrete structure is shown in figure 3. 


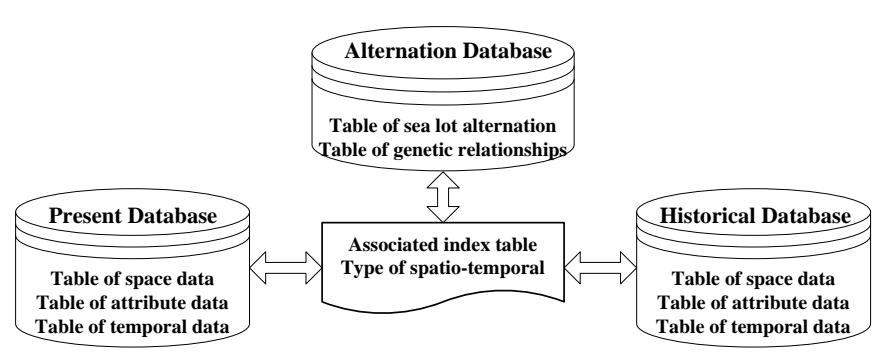

Fig.3 The structure of spatio-temporal database

The sea lot entity is divided into present sea lot entity and historical sea lot entity. They are stored in the present database and historical database in the way of multi-tables associated storage mode. At the same time, the sea lot alternation table and genetic relationship table are stored in the alternation database. The sea lot alternation table not only stores the change of sea area use data's spatial information and property information, but also stores the generation and disappearance of sea lot entity. In the alternation database, we can query, retrospect, statistic and analysis all of those information effectively. The genetic relationship table mainly stores the father-and-son relationship between present sea lot and historical sea lot. The two tables play an important role in the design of sea area use spatio-temporal database, not only records the affinity inheritance relationship between sea lot objects, but also establish corresponding relations between the historical data and present data. Meanwhile, the two table can meet the needs of data query about sea lot data. In addition, the database use the sea lot association index table to realize the dynamic query and correlation analysis among the present database, historical database and alternation database.

When the sea lot changed, it will need to update the sea area use data. First, the sea lot was transferred from present database to historical database. The old data was not deleted directly, thus to realize the data's incremental storage for query and historical backtracking. Meanwhile, added a record in the genetic relationship table of the alternation database, which describe the associated information between father-sea-lot and son-sea-lot. Through the alternation database to construct connecting bridge between present database and historical database, solve the problems of historical data's storage and present data's updating about sea lot entity.

\section{EXAMPLE ANALYSIS}

Take an example to verity and analysis the correction of sea area use spatio-temporal database organization method. The six state of T1 to T6 represent five different kinds of sea lot alternation separately, including sea lot merging, sea lot splitting, the change of sea lot ownership, new sea lot generation, old sea lot disappearance and so on. The alternation situation can be shown in Figure 4.

In the spatio-temporal database of sea area use management, setting $\mathrm{T}$ as time, $\mathrm{T} 1$ represents the initial state, and T2, T3, T4, T5, T6 represents alternation process in different moment. The ID means sea lot's identification code, which is exclusive by one sea lot and throughout the whole life cycle. As can be seen from the Figure 4, it describes the alternation process of one region of sea use.

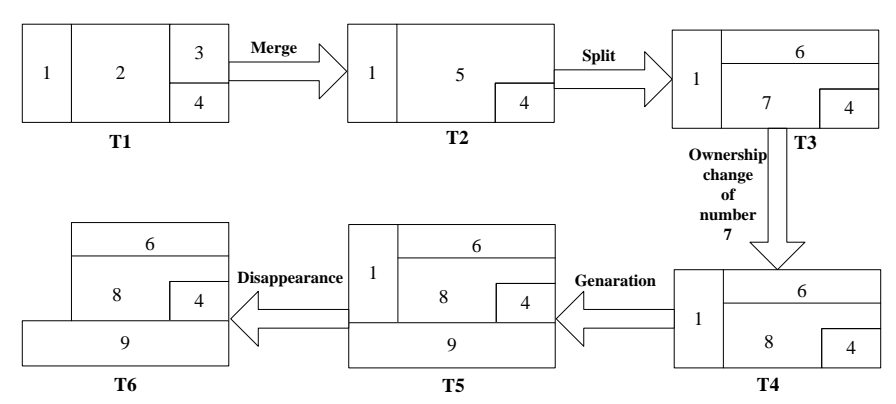

Fig.4 The schematic diagram of sea lot alternation

Using the existing mature relationship database to store and manage the sea area use spatio-temporal data, so that the space data and non-space data can be integrated seamlessly. At the same time, we can use the extended SQL language to query and retrieve the spatio-temporal data. According to the process of sea lot alternation, the storage situation of present database, historical database and alternation database are shown in table 1 to table 3 . Through the father ID and son ID in the alternation database, the present database and historical database are associated closely. As can be seen from the table, the database design method proposed by this paper can effectively realize the sea area use spatio-temporal data's organization and management, facilitating to the database's updating and maintenance, and in favor of spatio-temporal query and historical retrospect of sea lot data.

TABLE I. THE PRESENT DATABASE OF SEA LOT DATA

\begin{tabular}{|c|c|c|c|c|c|}
\hline ID & Owner & $\begin{array}{c}\text { Type of } \\
\text { sea use }\end{array}$ & $\begin{array}{c}\text { Certificate } \\
\text { number }\end{array}$ & $\begin{array}{c}\text { Depart- } \\
\text { ment }\end{array}$ & $\begin{array}{c}\text { The } \\
\text { others }\end{array}$ \\
\hline 4 & Huang & Fishery & 04320623046 & RuDong & $\cdots \cdots$ \\
\hline 6 & Wang & Fishery & 05320623019 & RuDong & $\cdots \cdots$ \\
\hline 8 & $\mathrm{Xu}$ & Reclamation & 06320623055 & RuDong & $\cdots \cdots$ \\
\hline 9 & Yang & Reclamation & 06320623086 & RuDong & $\cdots \cdots$ \\
\hline
\end{tabular}

TABLE II. THE HISTORICAL DATABASE OF SEA LOT DATA

\begin{tabular}{|c|c|c|c|c|c|}
\hline ID & Owner & $\begin{array}{c}\text { Typeof } \\
\text { sea use }\end{array}$ & $\begin{array}{c}\text { Certificate } \\
\text { number }\end{array}$ & $\begin{array}{c}\text { Depart- } \\
\text { ment }\end{array}$ & $\begin{array}{c}\text { The } \\
\text { others }\end{array}$ \\
\hline 1 & Qin & Fishery & 04320623037 & RuDong & $\cdots \cdots$ \\
\hline 2 & Zhou & Fishery & 04320623042 & RuDong & $\cdots \cdots$ \\
\hline 3 & Zhang & Fishery & 04320623045 & RuDong & $\cdots \cdots$ \\
\hline 5 & Jin & Fishery & 04320623076 & RuDong & $\cdots \cdots$ \\
\hline 7 & Liu & Fishery & 05320623020 & RuDong & \\
\hline
\end{tabular}

TABLE III. THE ALTERNATION DATABASE OF SEA LOT DATA

\begin{tabular}{|c|c|c|c|c|}
\hline Father ID & Son ID & Alternation & Time & Other \\
\hline 2 & 5 & Merge & $2004-09-16$ & $\cdots \cdots$ \\
\hline 3 & 5 & Merge & $2004-09-16$ & $\cdots \cdots$ \\
\hline 5 & 6 & Split & $2005-03-25$ & $\cdots \cdots$ \\
\hline 5 & 7 & Split & $2005-03-25$ & $\cdots \cdots$ \\
\hline 7 & 8 & Owner change & $2006-06-08$ & $\cdots \cdots$ \\
\hline- & 9 & generation & $2006-10-19$ & $\cdots \cdots$ \\
\hline 1 & - & disappearance & $2006-12-05$ & $\cdots \cdots$ \\
\hline
\end{tabular}




\section{CONCLUSION}

According to the needs of sea area use spatio-temporal data's dynamic management, based on the analysis of characteristics of spatio-temporal data, this paper from the perspective of sea lot alternation combines the base state with amendments model to design and construct sea area use spatiotemporal database. The spatio-temporal database is divided into persent database, historical database and alternation database. Through the effective organization, the temporal problem of sea lot alternation can be solved in a very good way. This method has the following advantages:

(1) The time information, space information and attribute information are stored separately in the way of multi-tables associated mode. The three tables are linked by the exclusive sea lot identification code, thus time characteristics, space characteristics, and attribute characteristics form a trinity, which facilitates mutual inquires of each other.

(2) It is easy to realize historical retrospect about sea lot data, and historical information can be effectively retrieved by various combinations of simple queries and inquiries, which including time-point-based query and time-period-based query.

(3) There is no need to store the spatio-temporal topological relationships between father-sea-lot and son-sea-lot. When carry out the sea lot data's historical retrospect, the space operation is not required, consequently reducing the data storage space and redundancy. Adapting this way, the data structure is extraordinary simple and has high efficiency.

\section{REFERENCES}

[1] LIANG Juanzhu, TU Ping, "Spatio-temporal data organization and query of sea lot in sea area use management", Journal of Geomatics, Vol.31 No.6, pp.3-5, Dec. 2006

[2] HUANG Dongmei, WANG Ruiqi, "Spatio-temporal data model in sea area use management based on event semantics", Computer Science, Vol.35 No.4B, pp.38-40, 2008

[3] SONG Wei, WANG Jiayao,"Cadstral spatio-temporal database organiz-

ation based on spatial database", Journal of Institute of Surveying and Mapping, Vol.22 No.2, pp.142-144, Jun.2005

[4] HUANG Yongqi, CUI Weihong, "Research on realizing spatialtemporal database based on historical relational database", Journal of Remote Sensing, Vol.12 No.5, pp.759-764, Sep.2008'

[5] ZHANG Feng, LIU Nan, LIU Renyi, and TANG Yuanbin, "Research of cadastral modelling and database updating based on spatio-temporal process", Acta Geodaetica et Cartographica Sinica, Vol.39 No.3, pp.303-309, Jun.2010

[6] LEI Qihong, LIU Yaolin, YIN Zhangcai, and HE Jianhua, "Spatio-temporal data model in cadastral information system based on weighted graph", Geomatics and Information Science of Wuhan University, Vol.31 No.7, pp.640-642, July 2006

[7] WU Wenjie, DONG Zhengbin, ZHANG Wenzhong, and JIN Fengjun, MAXiujun, XIE Kunqing, "Spatio-temporal evolution of the china's inter-urban organization network structure: based on aviation data from 1983 to 2006", Acta Geographica sinica, Vol.66 No.4, pp.435-445, Apr.2011

[8] LI Jun, SU Guozhong, NI Ling, "Cadastral spatial temporal model and parcel changing", Science of Surveying and Mapping, Vol.33 No.1, pp.221-223, Jan.2008

[9] ZHANG Baocai, ZHOU Shunping, WANG Yu, and YANG Lin, SONG Zongxiao, "Research on spatial-temporal data managemenat based on history archiving",Chinese Journal of Engineering Geophysics, Vol.6 No.1, pp.63-67,Feb.2009 